\title{
Assessment of Genetic Variability in Sorghum Accessions (Sorghum bicolor L. Moench) at the National Centre for Genetic Resources and Biotechnology, Ibadan, Nigeria
}

\section{${ }^{1}$ SIFAU, MO; ${ }^{2}$ ODUOYE, OT; ${ }^{2}$ OLUWASANYA, OA; ${ }^{2}$ ALADELE, SE}

\author{
${ }^{a}$ Department of Cell Biology and Genetics, University of Lagos, Akoka, Lagos. \\ ${ }^{b}$ Molecular Biology Laboratory, Biotechnology Unit, National Centre for Genetic Resources and Biotechnology (NACGRAB), Ibadan, Nigeria. \\ Corresponding Author: Sifau, Mutiu Oyekunle, mosifau@gmail.com
}

\begin{abstract}
The determination of genetic variation using molecular markers has been found to facilitate the conservation of crops and ensure food security. Genetic diversity among 80 accessions of S. bicolor in the gene bank of National Centre for Genetic Resources and Biotechnology (NACGRAB) Ibadan, was studied using 5 pairs of simple sequence repeat (SSR) markers. The polymorphic information content (PIC) of individual primer ranged from 0.34 to 0.70 with a mean value of 0.54 indicating enough diversity or variability among the accessions studied. The binary matrix obtained from the gel profiles generated a dendrogram which was made up of 4 clusters and one ungrouped accession at 0.66 coefficients of similarity. From the clustering pattern, 7 pairs of accessions were found to be $100 \%$ similar. Each similar pairs were subsequently merged together and reduced to a total of 7 accessions. However, it was also observed that the geographical location of collection of accessions did not affect the clustering pattern. The information obtained from this study could serve as the basis for the improvement and breeding programs of Sorghum to achieve food security in the country, and by extension, worldwide. ( ) JASEM

https://dx.doi.org/10.4314/jasem.v21i6.25
\end{abstract}

Keywords: Sorghum; Simple Sequence Repeat markers; Genetic variation; Polymorphic Information Content; Coefficient of similarity.

Sorghum bicolor L. Moench, commonly called Guinea corn is one of the most important staple food crops in Nigeria especially in Northern states that covers the guinea savannah ecological zone (FAO, 2004). It is a tropical plant belonging to the family Poaceae. Its usage as staple food is not limited to Nigeria alone as it is also a food crop of millions of the poor in semi-arid tropics of Africa, Asia and Latin America and it is the fifth in acreage among the world cereals (Anglani, 1998). Sorghum includes the cultivated grain races, and is a diploid, highly self-pollinated plant. It also possesses considerable diversity in morphological and agronomic traits, such as adaptive pest resistance (El-Awady et al., 2008). Upon this information, El-Awady et al., (2008) stated that the wide range of genetic diversity of Sorghum could be exploited as a possibility of improving its productivity as well as studying its diversity.

Many studies have been devoted to assessing the patterns of Sorghum genetic variation based on morphology (Djè et al., 1998) or pedigree (Jordan et al., 1998). However, Smith et al., (2000) reported that phenotypic variation does not reliably reflect genetic variation because of the role of environmental interaction in determining the phenotype. To enhance the breeding programs of any crop plant, the usage of modern techniques such as molecular markers is required. In recent years, the number of molecular assays available for application in area of breeding has increased dramatically, with each method differing in principles, applications, type and amount of polymorphism detected, as well as cost and time requirements (Karp et al., 1996). Some of these DNAbased techniques include Restriction Fragment Length Polymorphism (RFLP), Random Amplified Polymorphic DNA (RAPD), Simple Sequence Repeat (SSR), Amplified Fragment Length Polymorphism (AFLP) etc (Botstein et al., 1980).

According to Gupta and Varshney (2000), among these techniques, SSR (also known as microsatellites) represents an ideal marker system. This is due to its codominant inheritance, multi-allelic characters, occurrence in high frequency, locus specificity and distribution throughout the genomes of all higher plants and animals. Rakshit et al. (2012a) also stated that SSRs are most commonly used among different DNA markers because they are hypervariable, robust, chromosome specific and has widely been used for assessment of diversity in several cultivated crop species including Sorghum. Brown et al. (1996) had earlier reported that SSR also displays a high level of polymorphism, even among closely related accessions, and readily responds to simple and inexpensive polymerase chain reaction (PCR) assays. Therefore, SSR have been established as useful genetic markers in many plant species (Cregan et al., 1999) and in genetic mapping initiatives for cereals including Sorghum (Smith et al., 2000).

It is against this backdrop that this project was aimed at characterizing through SSR primers with a view to assessing the genetic diversity within and among clusters of accessions of Sorghum germplasm collected 
across Nigeria and conserved at the National Centre for Genetic Resources and Biotechnology, Ibadan, Oyo

\section{MATERIALS AND METHODS}

Eighty (80) sorghum accessions used for this study were collected from gene bank of National Centre for Genetic Resources and Biotechnology (NACGRAB) Moor Plantation Ibadan (Table 1). The accession numbers were well written out on each accession, and this was carefully followed during analysis to avoid any mix-up.

Deoxyribonucleic acid (DNA) Extraction: Total genomic DNA was extracted from the dry seeds of sorghum accessions following a modified Cetyltrimethyl Ammonium Bromide (CTAB) protocol of Doyle and Doyle (1990). The extracted DNA concentration and purity level was estimated through Nanodrop spectrophotometer (Thermo Scientific NanoDrop ${ }^{\mathrm{TM}}$ 2000) and on 1\% agarose gel electrophoresis.

Polymerase Chain Reaction (PCR) Amplification: Five primer pairs of Microsatellite markers were used (Table 2) to amplify the genomic DNA of all accessions. The polymerase chain reaction (PCR) was performed in a $13 \mu 1$ mixture containing $1 \mu 1$ of template DNA, $5 \mu 1$ of ready to use master mix, $5 \mu 1$ of double distilled water, $1 \mu l$ forward primer and $1 \mu l$ reverse primer. Amplification was performed on the thermal cycler (Eppendorf AG Mastercycler Nexus Gradient, 22331, Hamburg) using initial denaturation temperature of $94{ }^{\circ} \mathrm{C}$ for $1 \mathrm{~min}$; primer annealing temperature $51^{\circ} \mathrm{C}$ for $1 \mathrm{~min}$; extension $72{ }^{\circ} \mathrm{C}$ for $20 \mathrm{~s}$; and a final extension at $72^{\circ} \mathrm{C}$ for 10 mins.

Thereafter, the amplicon were checked on $1.5 \%$ agarose gel electrophoresis, viewed and photographed using Gel Documentation and Analysis Systems (UVdoc, GA-9000/9010 Version 12).

Data Analysis: Genetic diversity was estimated by scoring distinct and clear DNA bands on the photographs of gel profile (Figure 1) obtained from electrophoresis, to generate binary data tables allocating a 1 point where the band is present and 0 point when the band is absent. The scores were then exported to the NTSYS-pc 2.02j software package (Rohlf, 1996). The dendrogram generated from the matrix grouped the test lines using Unweighted Pair Group Method with Mathematic Average (UPGMA) on the basis of genetic similarity and Jaccard's coefficient. Data analysis to estimate the genetic distance among accessions was achieved by cluster analysis, which is an example of multivariate method, as described by Mohammadi and Prasanna (2003). So also the polymorphic information content (PIC) was calculated for individual primer using GenStat Discovery Edition 4 software

\section{RESULTS AND DISCUSSION}

The PIC values for individual primer ranged from 0.34 to 0.70 with a mean value of 0.54 (Table 3 ). An estimation of genetic coefficients of similarity, with values ranging from 0.5 to 0.94 revealed a range of variability in this collection of sorghum accessions. The dendrogram generated from the gel profiles revealed that at a coefficient of similarity of $0.66(66 \%)$, four clusters and one ungrouped (U) accession were distinguishable (Figure 2).
Table 1: The accession number and location of collection of \begin{tabular}{|l|l|l}
\multicolumn{3}{c}{ sample as documented in the NACGRAB Gene Bank. } \\
\hline S/N & ACCESSION NO. & LOCATION/ STATE
\end{tabular}

\begin{tabular}{|c|c|c|}
\hline S/N & ACCESSION NO. & LOCATION/STATE \\
\hline 1 & NG/SA /0095 & Owena / ONDO \\
\hline 2 & NG/SA /0093 & Olode garage/ OSUN \\
\hline 3 & NG/SA /0016 & Olode garage/ OSUN \\
\hline 4 & NG/SA /0098 & Nuhubamali/ KADUNA \\
\hline 5 & NG/SA/0071 & Ife garage / OSUN \\
\hline 6 & NG/SA /0083 & Epini Akoko farm / ONDO \\
\hline 7 & NG/AU/001 & Ogbose/ ONDO \\
\hline 8 & NG/AA/007 & Modakeke / OSUN \\
\hline 9 & NG/AA/010 & Ede / OSUN \\
\hline 10 & NG/AO /0001 & Nuhubamali/ KADUNA \\
\hline 11 & NG/AO/0004 & Kangara town/ NIGER \\
\hline 12 & NG/AA/0009 & Ejigbo/ OSUN \\
\hline 13 & NG/SA /0069 & Olode garage/ OSUN \\
\hline 14 & NG/AU/004 & Ogbose/ ONDO \\
\hline 15 & NG/SA /0074 & Ife garage isale / OSUN \\
\hline 16 & NG/AO/119 & Owena / ONDO \\
\hline 17 & NG/TO/005 & Olode egarage/ OSUN \\
\hline 18 & NG/SA /088 & Olode garage/ OSUN \\
\hline 19 & NG/AA/039 & Ife garage isale / OSUN \\
\hline 20 & $\mathrm{NG} / \mathrm{AO} / 113$ & Epini akoko farm $1 /$ ONDO \\
\hline 21 & NG/SA /0143 & Owena / ONDO \\
\hline 22 & NG/AU/003 & Ogbose/ ONDO \\
\hline 23 & NG/SA/0204 & Owena / ONDO \\
\hline 24 & NG/AA/158 & Atakumosa / OSUN \\
\hline 25 & NG/AO/0030 & Gargaurawa / JIGAWA \\
\hline 26 & NG/SA/0228 & kwali area/ FCT \\
\hline 27 & NG/AA/0011 & Ile Ife / OSUN \\
\hline 28 & NG/SA/078 & Ile Ife / OSUN \\
\hline 29 & NG/AA /159 & Atakumosa / OSUN \\
\hline 30 & NG/AO/0001 & Ijaye / OYO \\
\hline 31 & NG/AO/0001 & Oja okoru / ONDO \\
\hline 32 & NG/AU/002 & Ogbose/ ONDO \\
\hline 33 & NG/EO/013 & Mokowa/ NIGER \\
\hline 34 & NG/AA/163 & Igede Ekiti/ EKITI \\
\hline 35 & NG/OE/0002 & Omi Adio/ OYO \\
\hline 36 & NG/AT/020 & Olodo/ OGUN \\
\hline 37 & NG/SA/0077 & Gargaurawat/ JIGAWA \\
\hline 38 & NG/SA/0083 & NA \\
\hline 39 & NG/OE/001 & Omi Adio / OYO \\
\hline 40 & NG/AO/0015 & NA \\
\hline 41 & NG/AA/161 & Oja Oba Ado/ EKITI \\
\hline 42 & NG/OJ/009 & Gargaurawa / JIGAWA \\
\hline 43 & NG/SA/0081 & Kwali area/ FCT \\
\hline 44 & NG/AA/ 035 & Ife Garage Isale / OSUN \\
\hline 45 & NG/AA/ 0036 & Ife Oja Titun / OSUN \\
\hline 46 & NG/TO/ 008 & Omi Adio / OYO \\
\hline 47 & NG/AO/ 0114 & NA \\
\hline 48 & NG/SA/ 0083 & Zuba Vill / FCT \\
\hline 49 & NG/SA/ 0137 & Zuba Vill/FCT \\
\hline 50 & NG/SA/ 0109 & Dankaku Vill/ KANO \\
\hline 51 & NGB/06/ 016 & Dankaku Vill/ KANO \\
\hline 52 & NG/SA/ 0185 & Gargaurawa/ JIGAWA \\
\hline 53 & NG/SA/ 0236 & Kwali Area/ FCT \\
\hline 54 & NG/SA/ 0130 & Dankaku Vill/ KANO \\
\hline 55 & NG/SA/ 0168 & Danladi G Vill/ BAUCHI \\
\hline 56 & NG/SA/ 0093 & Danladi G Vill/ BAUCHI \\
\hline 57 & NGB/06/ 015 & Ife Oja Titun / OSUN \\
\hline 58 & NG/SA/ 0016 & Omi Adio / OYO \\
\hline 59 & NGB/06/ 015 & N/A \\
\hline 60 & NG/SA/ 0183 & Gwagwalada/FCT \\
\hline 61 & NG/SA/ 0224 & Gwagwalada/FCT \\
\hline 62 & NG/SA/ 0144 & Tsaida Vill/KANO \\
\hline 63 & NG/SA/ 0055 & Mokwa Kad Rd/ NIGER \\
\hline 64 & NG/SA/ 0275 & Okene/ KOGI \\
\hline 65 & NG/SA/ 0213 & Kasaranmi Vill/ KADUNA \\
\hline 66 & NG/SA/ 0240 & Oka Akoko/ ONDO \\
\hline 67 & NG/SA/ 0218 & Zuba Vill/ FCT \\
\hline 68 & NG/SA/ 0137 & Gadadi Vill, Duste/ JIGAWA \\
\hline 69 & NG/SA/ 0025 & Mile 5 Ncri/ MOKWA \\
\hline 70 & NG/SA/ 0040 & Zuba Vill/ FCT \\
\hline 71 & NG/SA/ 0071 & Babalomo/ MOKWA \\
\hline 72 & $\mathrm{NG} / \mathrm{SA} / 0063$ & Mokwa/ NIGER \\
\hline 73 & NG/SA/ 0126 & Wasai Minijibri/ NIGER \\
\hline 74 & NG/SA/ 0095 & Nuhubamali/ KADUNA \\
\hline 75 & NG/SA/ 0047 & Kangara Town/ NIGER \\
\hline 76 & NG/SA/ 0098 & Nuhubamli/ KADUNA \\
\hline 77 & NG/SA/ 0096 & Kangara Town/ NIGER \\
\hline 78 & NGB/06/ 020 & Kangara Town/ NIGER \\
\hline 79 & NG/SA/ 0004 & Fasola Settlement/ OYO \\
\hline 80 & NG/SA/ 10094 & Mokwa/ NIGER \\
\hline
\end{tabular}


Cluster 1 has the highest number of accessions of 35 while cluster 2 has the lowest with 7 accessions. Clusters 3 and 4 have 30 and 8 accessions respectively. From the clustering pattern also, 14 accessions were found to be $100 \%$ similar. They are 23 and 24; 63 and 67; 51 and 52; 71 and 78; 76 and 80; 72 and 74 and, 41 and 42 . However, it was also observed that the geographical location of collection of accessions did not affect the clustering pattern. This is evident as accessions from the same geographical area did not necessarily cluster together.

Table 2: List of SSR Primers for Sorghum amplification

\begin{tabular}{|c|c|c|c|c|}
\hline S/N & Primer I.D & Sequence & Molecular Weight & Tm (Min/Max) \\
\hline \multirow{2}{*}{1} & \multirow{2}{*}{$\mathrm{A}$} & F-GACAACTGTGTGGACCGATG & 500.23 & $58.35 / 58.35$ \\
\cline { 3 - 5 } & & R-CAGGGCTTTGAACCCAAATA & 374.37 & $58.35 / 58.35$ \\
\hline \multirow{2}{*}{2} & $\mathrm{~B}$ & F-GCTGCGGAATCTTCTACTGG & 357.74 & $62.45 / 62.45$ \\
\cline { 3 - 5 } & & R-CAGGGCTTTGAACCCAAATA & 461.69 & $58.35 / 58.35$ \\
\hline \multirow{2}{*}{3} & $\mathrm{C}$ & F-GTGGACCGATGGGCTTACTA & 615.24 & $62.45 / 62.45$ \\
& & R-CAGGGCTTTGAACCCAAATA & 363.96 & $58.35 / 58.35$ \\
\hline \multirow{2}{*}{4} & \multirow{2}{*}{5} & F-GACAACTGTGTGGACCGATG & 342.14 & $58.45 / 62.45$ \\
\cline { 3 - 5 } & & R-GGGCTTTGAACCCAAATACA & 478.74 & $62.45 / 62.45$ \\
\cline { 3 - 5 } & & F-CGATGGGCTTACTAGCCTTG & 400.32 & $58.35 / 58.35$ \\
\hline
\end{tabular}

Legend: $\mathrm{Tm}=$ melting temperature $($ minimum/maximum) of the primer

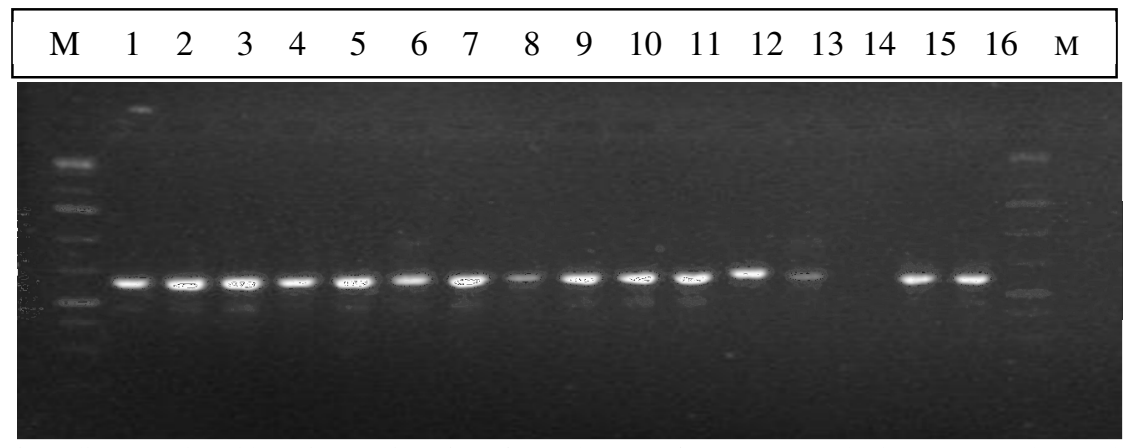

Fig 1: Gel profile of amplicon produced by primer pair A for 16 samples on $1.5 \%$ Agarose gel where $\mathrm{M}=100 \mathrm{bp}$ Marker; 1 - 16 are bands produced by amplicon from 16 samples. NB: The comb used can only take maximum of 16 samples at a time.

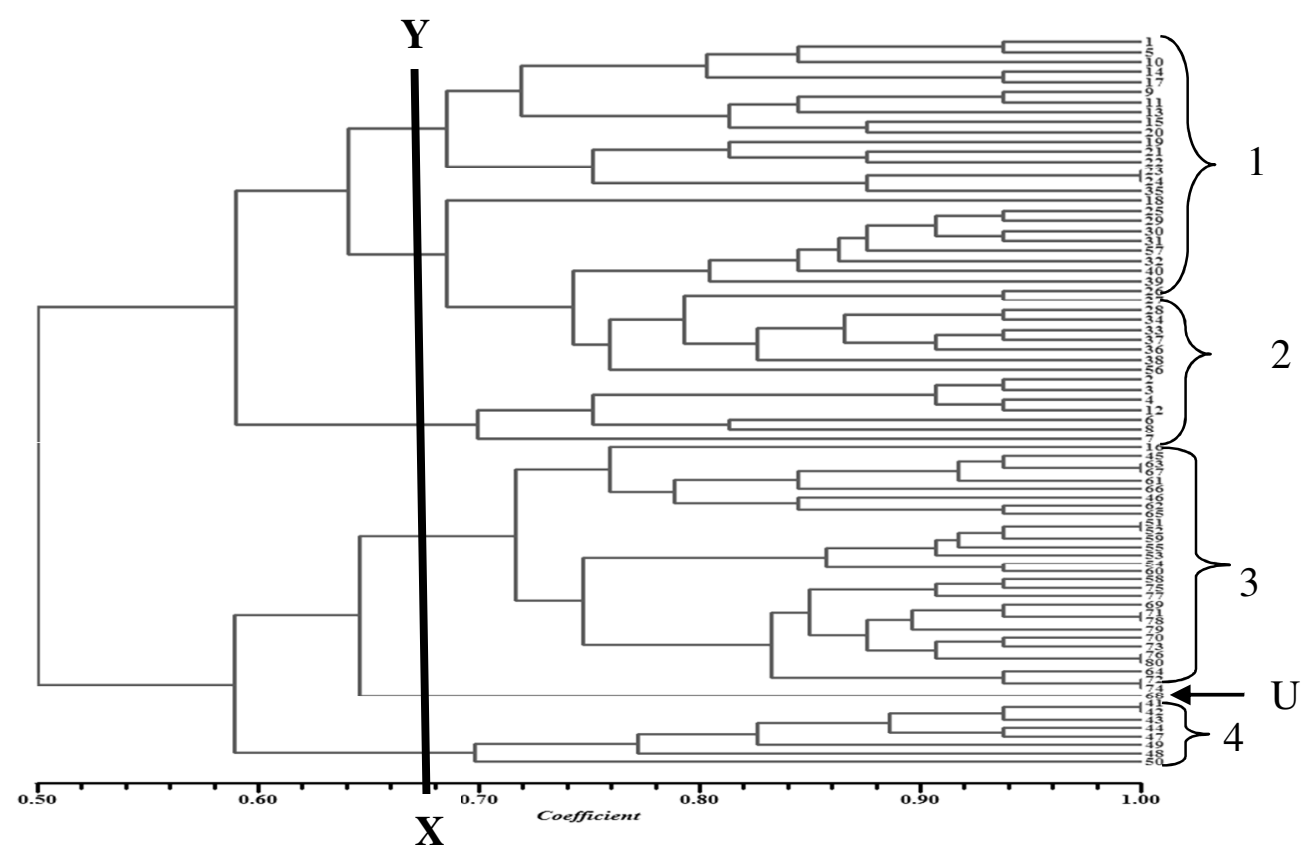

Fig 1: A UPGMA Dendrogram Showing the clustering pattern obtained from SSR primers among the 80 accessions of Sorghum studied. 
Legend: XY represents truncated line at a similarity coefficient of $66 \%$; 1 to 4 represents the four clusters and one ungrouped $(\mathbf{U})$ that were distinguishable among the accessions at $66 \%$ co-efficient of similarity.

Molecular markers have been used because of their ability to give a clearer and better picture of genetic diversity, though a combination of molecular markers and phenotypic analyses have proved to be a more powerful tool in explaining genetic diversity and relationships among sorghum accessions (Burow et al., 2012). SSR marker is said to be the most variable component of the genome with a high rate of molecular evolution, and as such has been used in characterization of many organisms especially eukaryotes (El-Awady et al., 2008). Qureshi et al. (2004) had stated that slippage of the DNA polymerase that occurred during replication of unequal crossing over resulting in differences in the copy number of the core nucleotide sequence is believed to be responsible for the microsatellite variation.

The 80 sorghum accessions evaluated in this study were uniquely differentiated using the 5 pairs of SSR markers. The average PIC value of 0.54 for all the primers showed that they are polymorphic though with different levels of polymorphism, thus revealing a high level of diversity among the accessions studied. Previous studies have equally come up with findings in support of wide genetic variation in collections of indigenous sorghum as evident from this study. For instance, Folketsma et al. (2005) reported large genetic diversity as well as predominance of rare alleles among guinea race of sorghum collected from various parts of the world. Barnaud et al. (2007) had also documented the existence of high genetic variation in sorghum landraces from Burkina Faso and Cameroon respectively, even in areas of relatively small sorghum cultivation. However, moderate diversity was found by Menz et al. (2004) among the sorghum inbreds developed in the US, and also Burow et al. (2012), who worked on collection of Chinese sorghum landraces.

The fourteen accessions found to be $100 \%$ similar were subsequently merged together and reduced to 7 accessions. This result is in agreement with studies in other species such as soybeans, barley and corn (Powell et al., 1996; Wu and Tanksley, 1993).

Table 3: The polymorphic information content (PIC) of individual markers used to assess the diversity of 80 sorghum accessions

\begin{tabular}{lrrrrrrrr}
\hline SSR Marker & $\begin{array}{c}\text { Major } \\
\text { Allele Freq. }\end{array}$ & $\begin{array}{c}\text { Genotype } \\
\text { No }\end{array}$ & No. of obs. & Allele No & $\begin{array}{c}\text { Availa- } \\
\text { bility }\end{array}$ & $\begin{array}{c}\text { Gene } \\
\text { Diversity }\end{array}$ & $\begin{array}{c}\text { Hetero- } \\
\text { zygosity }\end{array}$ & PIC \\
\hline A & 0.40 & 8.00 & 75.00 & 4.00 & 0.94 & 0.69 & 0.72 & 0.63 \\
B & 0.67 & 3.00 & 62.00 & 2.00 & 0.78 & 0.44 & 0.05 & 0.34 \\
C & 0.42 & 9.00 & 58.00 & 5.00 & 0.73 & 0.71 & 0.76 & 0.67 \\
& & & & & & & & \\
D & 0.38 & 5.00 & 69.00 & 3.00 & 0.86 & 0.66 & 0.46 & 0.59 \\
E & 0.51 & 4.00 & 71.00 & 3.00 & 0.89 & 0.54 & 0.55 & 0.44 \\
Mean & 0.48 & 5.80 & 67.00 & 3.40 & 0.84 & 0.61 & 0.51 & 0.54 \\
\hline
\end{tabular}

The clustering pattern was not affected by the location where samples were collected. This is evident because collections made from the same geo-political zone did not all occur in the same cluster; rather they are separated out in different clusters. This is in agreement with the findings of Singh et al., (2006).

The vast gene pool of Sorghum collection in NACGRAB has served several researchers and students from Research Institutes and tertiary institutions either for research and development or during their final year undergraduate projects respectively. The accessions that paired together at 1.0 coefficient of similarity could be having the same genotypes based on their $100 \%$ similarity. Further studies need to be carried out on them to ascertain their true genotypes especially those that will combine their morphological and molecular data. Until that is done, the accessions may not be supplied to researchers and project students alike as variants or as the same unit.
Conclusion: The SSR marker as used in this study was able to elucidate the genetic variation among the different sorghum accessions studied effectively. Insight into phylogenetic relationships among varieties and species of Sorghum could therefore be provided by the distribution and sequence of SSR markers. The information thereby obtained could be used in germplasm conservation and preservation for sustainable use of sorghum genotypes. It could also serve as baseline knowledge in Sorghum breeding works for crop improvement in Nigeria.

\section{REFERENCES}

Anglani, C (1998). Sorghum for human food: a review. Plant Foods Hum. Nutr., 52: 85-89.

Barnaud, A; Deu, M; Garine, E; McKey, D; Joly, HI (2007). Local genetic diversity of sorghum in a village in northern Cameroon: Structure and dynamics of landraces. Theoretical and Applied Genetics 114:237- 248. 
Botstein, DRL; White, MS; Davis, RW (1980). Construction of a genetic linkage map in man using restriction fragment length polymorphisms. American Journal of Human Genetics 32: 314-331.

Brown, SM; Hopkins, MS; Mitchell, SE; Senior, ML; Wang, TY; Duncan, RR; Gonzalez-Candelas, F; Kresovich, S (1996). Multiple methods for the identification of polymorphic simple sequence repeats (SSRs) in Sorghum (Sorghum bicolor (L.) Monech). Theoretical Application of Genetics 93: 190-198.

Burow, G; Cleve, DF; Zhanguo, X; John, JB (2012). Genetic Diversity in a Collection of Chinese Sorghum Landraces Assessed by Microsatellites. American Journal of Plant Sciences 3: $\quad$ 1722-1729.

Cregan, PB; Jarvik, IAL; Bush, RC; Shoemaker, KG; Lark, AL; Khler-Kaya, TT; Vantoai, DG; Lohnes, J; Specht, JE (1999). An integrated diversity in Sorghum germplasm from India. Gen. Res. Crop Evol., 43: 559567.

Djè, YM; Ater, C; Lefèbvre, C; Vekemans, X (1998). Patterns of morphological and allozyme variation in Sorghum landraces of Northwestern Morocco. Gen. Res. Crop Evol., 45: 541- 548.

El-Awady, M; Youssef, SS; Selim, EEM; Ghonaim, MM (2008). Genetic Diversity among Sorghum bicolor Genotypes Using Simple Sequence Repeats (SSRs) Markers. Arab J. Biotech. 11(2): 181-192.

FAO (2004). United Nations Food and Agriculture Organization. Retrieved from (http://faostat.fao.org).

Folketsma, RT; Rattunde, HFW; Chandra, S (2005).The pattern of genetic diversity of Guinea- race Sorghum bicolor (L.) Moench landraces as revealed with SSR markers. Theoretical Application of Genetics 111:399-409.

Gupta, PK; Varshney, RK (2000). The development and use of microsatellite markers for genetic analysis and plant breeding with the emphasis on bread wheat. Euphytica 113: $163-185$.

Jordan, DR; Tao, YZ; Godwin, ID; Henzel, RG; Cooper, M; McIntyre, CL (1998). Loss of genetic diversity associated with selection for resistance to Sorghum midge in Australia Sorghum. Euphytica 102: 1- 7.
Karp, A; Seberg, O; Buialli, M (1996). Molecular techniques in assessment of botanical diversity. Annals of Botany 78: $143-149$.

Mohammadi, SA; Prasanna, BM (2003) Review and Interpretation Analysis of Genetic Diversity in Crop Plants: Salient Statistical Tools. Crop Science 43: 12351248.

Menz, MA; Klein, RR; Unruh, NC; Rooney, WL; Klein, PE; Mullet, JE (2004). Genetic diversity of public inbreds of sorghum determined by mapped AFLP and SSR markers. Crop Science 44:1236-1244.

Powell, W; Morgante, M; Andre, C; Hanafey, M; Vogel, J; Tingey, S; Rafalski, A (1996). The comparison of RFLP, RAPD, AFLP and SSR (Microsatellite) markers for germplasm analysis. Mol Breed 2: 225-238.

Qureshi, SN; Saha, S; Kantety, RV; Jenkins, JN; Saha, S (2004). Molecular biology and physiology: EST-SSR: a new class of genetic markers in cotton. $J$ Cotton Sci.:8:112-123.

Rakshit, S; Gomashe, SS; Ganapathy, KN; Elangovan, M; Ratnavathi, CV; Seetharama, N; Patil, JV (2012a). Morphological and molecular diversity reveal wide variability among Sorghum Maldandi landraces from India. J Plant Biochem Biotechnol 21: 145-156.

Rohlf, FJ. (1996). NTSYS-pc: Numerical Taxonomy and Multivariate Analysis System, version 2.02j. Exeter Software. Setauket, New York.

Singh, AK; Singh, M; Singh, AK; Singh, R; Kumar, S; Kalloo, G (2006). Genetic Diversity within the Genus Solanum (Solanaceae) as Revealed by RAPD Markers. Current Science 90(5):711-716.

Smith, JSC; Kersovich, S; Hopkins, MS; Mitchell, SE; Dean, RE; Woodman, WL; Lee, M; Porter, K (2000). Genetic diversity among elite Sorghum inbred lines assessed with simple sequence repeats. Crop Sci. 40: 226-232.

Wu, KS; Tanksley, SD (1993). Abundance, polymorphism and genetic mapping of microsatellites in rice. Mol. Gen. Genet. 241: 